\title{
3D water quality modeling of a morphologically complex lake, sensitivity and uncertainty analyses, and examples of model applications
}

\author{
$\underline{\text { S. Missaghi }}^{\mathrm{a}}$ and M. Hondzo ${ }^{\mathrm{b}}$ \\ ${ }^{a b}$ University of Minnesota, St. Anthony Falls Laboratory, Third Ave. SE, Minneapolis, Minnesota
}

Email:miss0035@umn.edu

\begin{abstract}
Lake Minnetonka (44॰54N; 93॰41W; MN, USA) has been a major regional water resource since 1800s. Its hotels and resorts were replaced by large homes and estates by $1860 \mathrm{~s}$ and its $175 \mathrm{~km}$ shoreline well developed by 1930s. The lake has a complex morphometry with 26 bays and coves that has created a varying water quality regions and bottom sediment types. The lake and its catchment have been well studied; however, a lake water quality model had been lacking due to the lake's complex morphology. The goals of this project, Lake Minnetonka 3D water quality modeling, were to apply a model robust enough to capture the system's large water quality heterogeneity, conduct sensitivity analysis to increase confidence in the model results, and provide engineering application of the model to aid in management of the lake. We have successfully applied a coupled 3D hydrodynamic (ELCOM) and ecological (CAEDYM) model to a number of bays of Lake Minnetonka, including:
\end{abstract}

- $\quad$ parameter calibration and model confirmation (validation),

- model simulations and the insights gained about the biogeochemical processes,

- the sensitivity and uncertainty analyses by two methods and the model parameter ranking, and

- $\quad$ examples of ecological application of the model in Lake Minnetonka.

The results reflect a lake system with significant spatial and temporal water quality changes that requires the use of a 3D model. Spatial and temporal dynamics were well simulated and model output results of water temperature (T), dissolved oxygen (DO), total phosphorus (TP) and one group of algae (Cyanobacteria) as represented as chlorophyll $a(\mathrm{Chl} a)$ compared well with an extensive field data in the bays under two very meteorologically different growing seasons. The model was able to capture water quality variations including significant sudden (days) water quality changes caused by stream inflow events that would not have been otherwise detected by typical summer monitoring. Model simulations indicate that total phosphorus variations in deeper water columns were more likely the consequences of physical perturbations caused by storm events flows. The model captured the heterogeneity of the lake and showed that the use of 3D model along with an accurate bathymetry, and a systematic calibration and confirmation process can help to analyze the hydrodynamics of a morphologically complex lake.

Much effort was made in setting up and configuring the model, carrying out calibration, and confirmation. Two sensitivity and uncertainty methods were used to improve understanding of the model, identify influential model parameters, explore spatial and temporal variabilities of model prediction, and to rank 40 of the model parameters. $70 \%$ of model output uncertainty was explained by 7 parameters or less. T, DO, TP, and Chla model outputs contributed 3,13,26, and 58\% to total model variance respectively. Results identified the need for a better understanding of biological model parameters and the need to include bacteria and zooplankton simulations in future work. The spatial and temporal variations of model outputs were found to be sensitive to the hydrodynamics of physical perturbations such as those caused by stream inflows generated from storm events. 3D sensitivity-uncertainty analyses must include periods of physical perturbations.

The model has been used to examine and compare the coolwater fish habitat analysis in 3D and under a scenario where spatial heterogeneity has been eliminated by horizontally averaging T and DO. The model is currently used to investigate the relationship between climate change, shoreline plant survival, lake hydrodynamics, lake water level changes, sediment nutrient flux, and water quality.

Keywords: Lake morphometry, biogeochemical modeling, fish habitat, climate change, Lake Management 
Missaghi and Hondzo, 3D water quality modeling of a morphologically complex lake...

\section{INTRODUCTION}

Water quality models are essential tools that enable the water resource managers to study and extend understanding of physical, chemical, and biological processes of the ecological systems ( $\mathrm{Li}$ and $\mathrm{Wu}, 2006$; Gal et al, 2009). These models give meaning to our observations, enhance the interpretation of available data and allow evaluation of potential impacts of various proposed alternatives (Louks and Beek, 2005). Water quality models are increasingly playing a larger role in water resources management (Erturk, 2010) and are becoming the cornerstone of water resources planning. The results of such models are commonly integrated into a decision support system to meet regulatory requirements (Lung, 2001; Romero et al., 2006; Trolle et al., 2008), form environmental policies, and create consensus in water resources management.

Along with the traditional anthropogenic impacts, the new water resources management paradigm also includes both the climate change and the social economical factors in its evaluation of water resources. This new approach of water resources management or paradigm has created a need for an adaptive, flexible, and integrated water resources management (Pahl-Wostl et al., 2011) which requires a vast amount and diverse set of data (Argent and Houghto, 2001). Any water resources management scheme must also adjust simultaneously to these various factors or drivers of ecosystem in temporal and spatial scales that are useful to resource managers (Power et al., 2005). Models can be used to synthesize and integrate the information needed (Milly et al., 2008).

Additionally, the interaction and interactive feedbacks among the drivers of ecosystem is increased in morphologically complex lake systems where water quality is subjected to greater temporal and spatial variabilities. The increased water quality heterogeneity requires an accurate three-dimensional (3D) representation of physical, chemical, and biological processes. 3D models can also provide resolutions that capture individual morphological features such as bays and intra-lake circulations in of lakes with complex morphometry (Hodges et al., 2000). Aquatic systems reflect the effect of 3D hydrodynamics and ecological processes and therefore a 3D model is needed to capture these interactions.

Numerous 3D water quality models have been developed (Gaber, 2009) and applied (Hodges et al., 2000; Chen et al., 2002; Komatsu et al., 2006; Leon et al., 2011) throughout the world, many of them for the first time. To integrate the model results into a decision process, models need to be calibrated, confirmed (validated), and supported by sensitivity and uncertainty analyses (Arhonditsis and Brett, 2004; Saltelli et al., 2006; Salacinska et al., 2009). Climate change, in particular, has increased uncertainty in water resources management by altering the frame of references (boundary conditions) used to evaluate and manage risks to the water resources (Milly et al., 2008).

A series of recent research investigations has led to a successful application of a coupled 3D hydrodynamic and ecological model to number of bays of a morphologically complex lake. The investigations have included: parameter calibration and confirmation, model simulations, sensitivity, and uncertainty analyses by two methods, ranking of model parameters, and two examples of ecological applications of the model.

\section{THE STUDY AREA}

Lake Minnetonka (60 $\mathrm{km}^{2}$; $\left.44^{\circ} 54^{\prime} \mathrm{N} ; 93^{\circ} 41^{\prime} \mathrm{W}\right)$ has 23 bays, $200 \mathrm{~km}$ of shoreline, $24 \mathrm{~km}^{2}$ of littoral area, and a maximum depth of $34 \mathrm{~m}$ (MNDNR, 2007). The lake's watershed $\left(319 \mathrm{~km}^{2}\right)$ has an average precipitation rate of $750 \mathrm{~mm}$ delivering 10.8 tons (2006) of total phosphorus (TP) into the lake through five creeks (MCWD, 2008). The lake water quality heterogeneity lake is evident by the ten year (19992009) averages of water quality grades (Fig. 1).

\section{THE 3D WATER QULITY MODELING}

\subsection{Model Description Setup and Configuration}

The 3D hydrodynamic Estuary and Lake Computer Model (ELCOM) coupled with the ecological Computational Aquatic Ecosystem Dynamics Model (CAEDYM) are developed and maintained by the

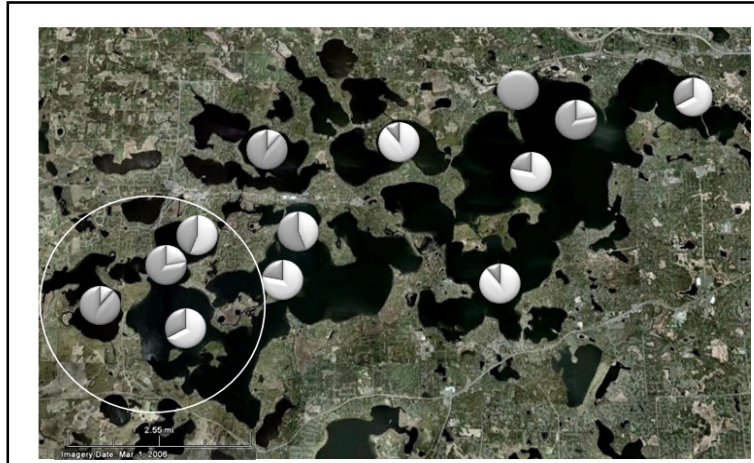

Figure 1. Map of Lake Minnetonka and the study area (circled), showing the water quality heterogeneity of the lake by the ten year (19992009) average quality indicators (pie charts: white is clear and gray is poor water quality.

Centre for Water Research of the University of Western Australia. Model overviews are well described by Gal et al. (2009) and Leon et al. (2011). The model was configured to model T, velocities, TP, total nitrogen $(\mathrm{TN}), \mathrm{pH}$, dissolved oxygen (DO), organic carbon, and one algal group (Cyanobacteria). The study area 
$(8.01 \mathrm{~km} 2)$ was discretized into $200 \mathrm{~m}$ surface grids with uniform $0.5 \mathrm{~m}$ vertical grids with a model simulation time step of 120 s. Calibration and confirmation periods were 205 days (Mar. 29-Oct. 20, 2000) and 168 days (Apr. 25-Oct. 10, 2005 ) respectively. Figure 2, illustrates a simplified conceptual diagram of the major processes modeled and configured.

\subsection{Model Parameter Estimation, Calibration, and Confirmation}

Published values of eighty model parameters along with their minimum, maximum, mean (reasonable values), number of samples (n), and standard deviation $(\sigma)$ were compiled. The weighted square sum (WSS) parameter estimation procedure, described by Omlin

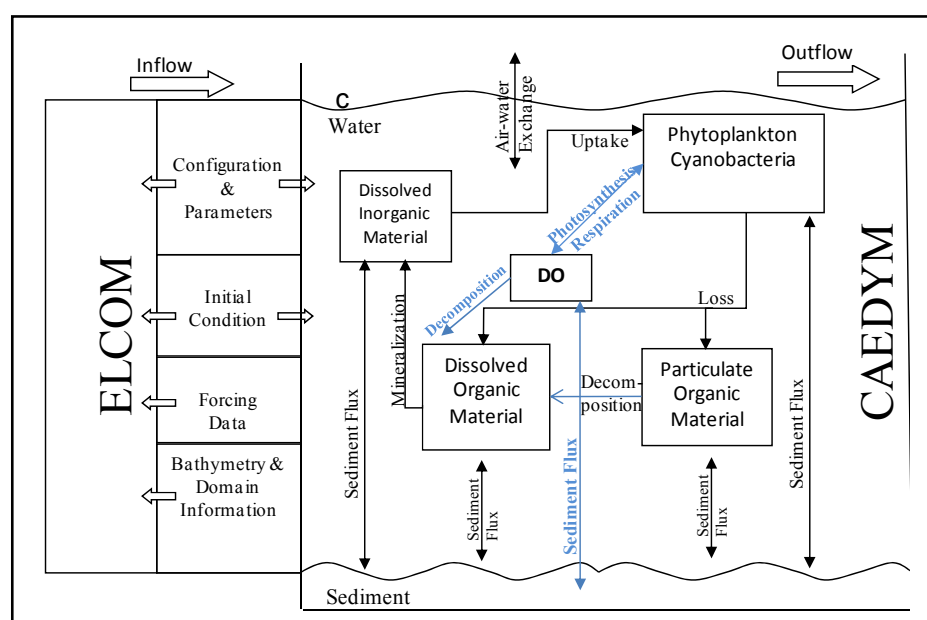

Figure 2. A conceptual diagram of major processes simulated in the coupled ELCOM-CAEDYM model.

et al. (2001), was used to assign an optimal (best fit) estimate of the model parameters:

$W S S(\theta)=\sum_{k=1}^{\mathrm{y}} \sum_{j=1}^{t} \sum_{i=1}^{z_{y_{k}}}\left(\frac{y_{\text {meas. },}, \mathrm{j}, \mathrm{i}-y_{k}\left(t_{j}, z_{y_{k_{i}}} \theta\right)}{\sigma_{\text {meas. } y_{k}}}\right)^{2}$

where the index $i$ represents the spatial (vertical) locations from 1 to the total number $\left(Z_{y_{k}}\right)$ of depth field sampling locations for model predicted variables $\left(y_{k}\right)$ where $k$ represents T, DO, TP, and Chla model outputs. Index $j$ is time $\left(t_{j}\right)$ from 1 to the total number of dates $(t)$ where measured profiles were used. Model predicted variables calculated with the parameter value $(\theta)$ are represented by $y_{k}\left(Z_{y_{k_{i}}}, t_{j}, \theta\right)$ and corresponds to the same location and time of the measured data $\left(y_{\text {meas.k }}, \mathrm{j}, \mathrm{i}\right)$.

The calibration process proved to be an iterative process that provides a great depth of understanding of the system (Hipsey et al., 2006). Coefficient of determination $\left(\mathrm{R}^{2}\right)$ of measured and simulated data $(\mathrm{T}, \mathrm{DO}, \mathrm{TP}$, and Chla) were used to measure the model goodness of fit (Fig. 3). Not all of a system's ecological nuances could be captured by a quantitative calibration. Therefore, much insight was gained by examining and evaluating the profiles of each model output against meteorological data and stream inflows into the lake. The profiles were qualitatively examined for patterns and times of maximum and minimum which is valuable in evaluating the simulated algal growth (Bruce et al., 2006; Hipsey et al., 2006).

\subsection{Results and Discussion}

Review of the measured stream flows revealed inaccuracies that were corrected to better reflect the actual field conditions and precipitation
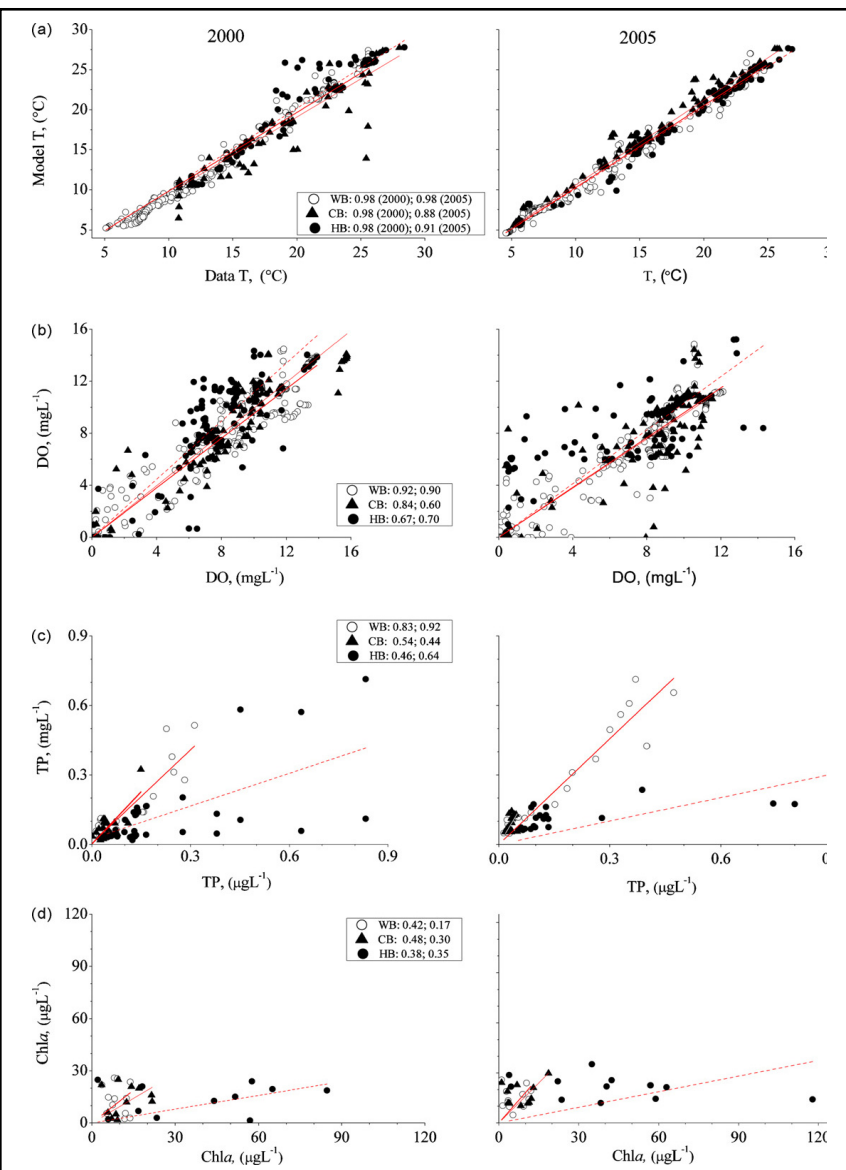

Figure 3. Comparison of measured data from 3 bays of West Upper Bay (WU), Cooks Bay (CB) and Halsted Bay (HB)) of Lake Minnetonka with the modeled (a) T, (b) DO, (c) TP, and (d) Chla and their respective $\mathrm{R}^{2}$ for the years 2000 (calibration) and 2005 (confirmation). 
rates. The calibration (2000) and confirmation (2005) periods were hydrologically distinct seasons and the model accurately simulated the lake water levels for both periods (mean difference $=0.05 \mathrm{~m}$ ), reflecting a well balanced water budget.

Temperature predictions were excellent $\left(\mathrm{R}^{2}=0.98\right)$. DO profiles agreed well at all the three measuring locations (0.67-0.92) but missed gentle metalimnic oxygen peaks. TP (0.44-0.92) and Chla (0.3-0.48) agreed reasonably well (Fig. 3). Measured and modeled TP values showed that the each bay has distinct localized TP concentrations making the selection of sediment phosphorus release rate model parameter (SmpPO4) a balance between capturing the short term TP variations in as many locations as possible, capturing the general TP seasonal variations, and keeping SmpPO4 within the known regional values. Modeling biological biomass concentrations (Chla) are inherently difficult because of their lateral patchiness, vertical distributions, temporal variations (blooming) and the still evolving understanding of algae biological dynamics (Hipsey et al., 2006; Reynolds, 2006).

\subsection{Sensitivity and Uncertainty Analysis}

\section{Sensitivity and Uncertainty Analyses}

Sensitivity and uncertainty analyses quantify how sensitive the prediction variables (model outputs) are to changes in corresponding calibration parameters and how uncertain the model prediction is due to the variability of the calibration parameters (Melching and Bauwens, 2001; Cacuci, 2003; Arhonditsis and Brett, 2004; Saltelli et al., 2006; Manache and Melching, 2008). These analyses increase model reliability and can identify influential model parameters (Saltelli et al., 2000; Saloranta and Anderson, 2007; Zhang and Arhonditsis, 2009) and their results help to gain insight about the key processes of the system under study (Makler-Pick et al., 2011).

\section{Sensitivity and Uncertainty Methods}

Two different local sensitivity and uncertainty methods Mean Value First-Order Reliability (MFOR) and The Mean Square Root (MSQR) methods were used to evaluate 40 model parameters. The MFOR method (Melching and Bauwens, 2001) estimates the variance of the model output $\left(\sigma_{y_{k}}{ }^{2}\right)$ as:

$\operatorname{var}\left(y_{k}\right)={\sigma_{y_{k}}}^{2} \approx \sum_{\iota=1}^{p}\left(\left(\frac{\partial g\left(\theta_{l}\right)}{\partial \theta_{\iota}}\right)_{\theta_{m}} \sigma_{\iota}\right)^{2}$

Where model sensitivity, evaluated about the best fit values of model parameters $\left(\theta_{m}\right)$, is represented by $\frac{\partial g\left(\theta_{l}\right)}{\partial \theta_{\iota}}$ with $g(\cdot)$ as the function representing the model prediction variables. $\sigma_{y_{k}}$ is the standard deviation of $y_{k}$, and $\sigma_{\iota}$ is that of model parameters $\theta_{\iota}$ (derived from literature values).

The MSQR method (Omlin et al., 2001) allows a measure of sensitivity of $y_{k} \operatorname{siml}$ as influenced by $\theta_{\iota}$, by averaging the squares of the dimensionless error contributions of all corresponding model state and measured variables for all points in time and all sampling locations:

$\delta_{\theta_{\iota}}^{m s q r}(\theta)=\sqrt{\frac{1}{n} \sum_{k=1}^{y} \sum_{j=1}^{t} \sum_{i=1}^{Z_{y_{k}}}\left(\frac{\sigma \theta_{\iota}}{\sigma y_{k}} \frac{\partial g\left(\theta_{l}\right)}{\partial \theta_{\iota}}\left(t_{j}, Z_{y_{k_{i}}}, \theta\right)\right)^{2}}$

In both cases, the dimensionless fraction of variance (FOV) was used to evaluate the influence of each parameter $\left(\theta_{l}\right)$ within each of the four model outputs $\left(y_{k}\right)$ of $\mathrm{T}, \mathrm{DO}, \mathrm{TP}$, and Chla, and ranking the influence of model parameters on model predictions. The MSQR method was also used to calculate the FOV contributed by each model output $\left(y_{k}\right)$ to the total model variance which was further confirmed by the sensitivity index $\left(S_{\text {indx }}\right)$ of parameters (Chen et al., 2002; Bruce et al., 2006).

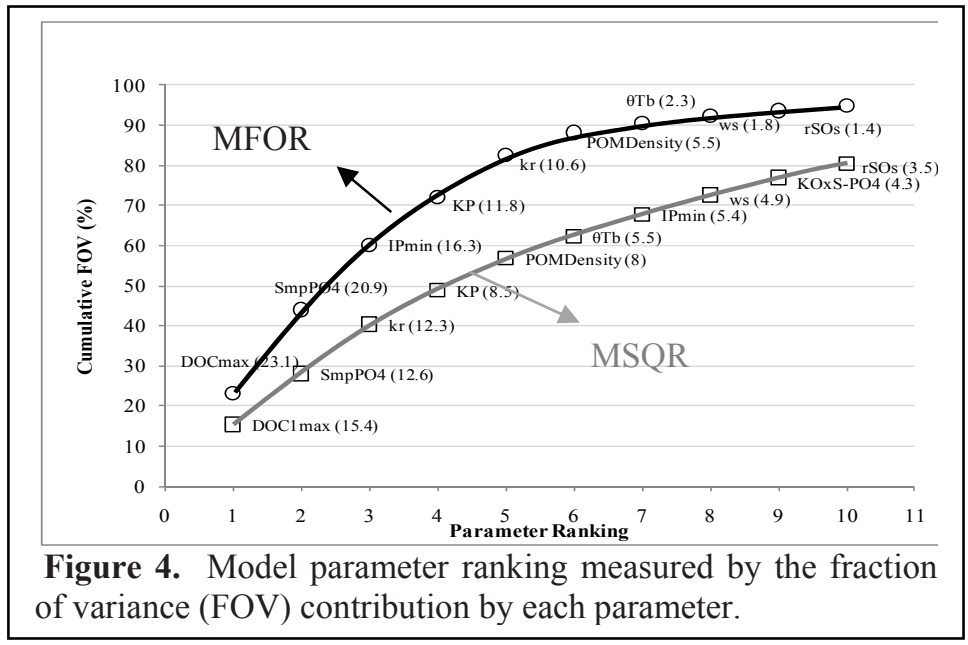




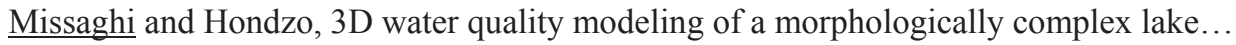

Forty of the best fit model parameters were included in the sensitivity and uncertainty analyses using the two methods of MFOR and MSQR. Their results agreed very well and the top influential model parameters were: the maximum mineralization of dissolved organic carbon to dissolved inorganic carbon (DOC1max), sediment phosphorus release rate model parameter (SmpPO4), minimum internal phosphorus concentration (IPmin), respiration mortality and excretion (kr), half saturation constant for phosphorus (KP), density of particulate organic matter particles (POMDensity), and temperature multiplier function for phytoplankton $(\theta \mathrm{Tb})$. The three model parameters of $\mathrm{IP}_{\min }, \mathrm{K}_{\mathrm{P}}$, and $\mathrm{DOC}_{1 \max }$ explained $75 \%$ of model predicted $\mathrm{T}$ variance. $\mathrm{DOC}_{1 \max }, \mathrm{K}_{\mathrm{P}}$, and $\mathrm{POM}_{\text {Density }}$ parameters contributed $65 \%$ of the variance observed in DO model output with $\mathrm{DOC}_{1 \max }$ as the most prominent parameter. $\mathrm{SmpPO}_{4}$ was the most influential model parameter in the TP output and along $\mathrm{POM}_{\text {Density }}$, and $\mathrm{DOC}_{1 \max }$ explained $85 \%$ of the variance of model predicted TP variable.

The three model parameters - $\mathrm{kr}, \mathrm{DOC}_{1 \max }$, and $\theta \mathrm{Tb}$ - contributed $55 \%$ of the observed variance in the model predicted Chla variable. The loss term $\mathrm{kr}$ had the greatest influence on Chla output, indicating the need for including zooplankton in simulations. Algal growth depends on availability and rate of mineralization $\left(\mathrm{DOC}_{1 \max }\right)$ and its magnitude is determined by $\theta \mathrm{Tb}$. The Chla output sensitivity was spread over a larger number of parameters, with almost $40 \%$ of the variance depending on all other lower ranking parameters. The analysis highlighted the need for a greater understanding and field measurement of biological model parameters. The biological parameter identifiability can further be complicated by feedback and interdependence among the model biological parameters (Beck, 1987; Mieleitner and Reichert, 2008).

The model outputs of T, DO, TP, and Chla contributed 3, 13, 26, and 58\% to total model variance, respectively. This corresponded with the model performance where $\mathrm{T}$ had the best fit and the biological component of the model had the least fit between the measured data and model output. Findings were supported by $S_{\text {indx }}$ which measured the parameters to which the model output is most sensitive.

\subsection{Model Application for Lake Minnetonka}

\section{Lake Minnetonka Coolwater Fish Habitat Analysis}

The 3D ELCOM-CAEDYM model was robust enough to capture the system's physical, chemical and biological seasonal as well as the short term duration (intra-seasonal) of spatial and temporal variations. The model results were used to analyze the coolwater fish habitat, fish typical of Lake Minnetonka, under two (2000 and 2005) climatologically different seasons. All control volumes with suitable fish habitat parameters ( $\mathrm{T}$ and DO) were indentified and tracked through the full simulation periods. The analysis showed a $62 \%$ increase in the undesirable coolwater fish habitat from year 2000 to 2005 . These changes were supported by a seasonal average of $2{ }^{\circ} \mathrm{C}$ warmer water temperatures and $1 \mathrm{mg} \mathrm{L}^{-1}$ lower DO levels of measured data in 2005. This is important as climate change now poses the greatest threat in altering water temperatures for the fish communities (Fairbairn, 2011).

\section{Impacts of Climate Change on Water Quality and Shoreline Vegetation of Lake Minnetonka}

Hydromodification, including water level fluctuations, alters lake's hydrodynamics and water quality (Brown and Caldwell, 2010; Coops et al., 2003; Harrison, 1989; EPA 2009) and directly influences the littoral plant communities (Keddy and Reznicek, 1986; Nilsson and Svedmark, 2002; Kirkman and Sharitz, 1992). Hydromodification is identified as the stressor for over $20 \%$ of the water quality impaired lakes in the United States and climate change is expected to exasperate the issue in Midwest USA (Fairbairn, 2011). Moreover, much effort is focused on safeguarding and restoring lake shorelines which might prove ineffective without choosing plants to match prevailing water level conditions (Vanderbosch and Galatowitsch; 2010). The effects of potential climate change on fluctuating lake water levels must be taken into consideration in designing and installing engineered shoreline restoration and preservation projects.

The 3D ELCOM-CAEDYM model of Lake Minnetonka is simulated under four different seasons to investigate the potential climate change impacts on the lake's water level and water quality. Three of the climatically different seasons are based on the fifth (dry), $95^{\text {th }}$ (wet), and the $50^{\text {th }}$ percentile (normal) of historical annual precipitations with the fourth season based on the predicted mid- $21^{\text {st }}$ century climate change scenario. Comparisons of historical dry (2000) and wet (2005) seasons show that the lake hydrodynamic and ecological processes are sensitive to mixing due to seasonal instream flows and wind variabilities. The predicted climate trends for the study area are amplified variations in precipitations, lake levels, instream flows, and soil moistures (Fairbairn, 2011). The 3D lake model will aid in developing lake management plans to adapt to the predicted climatic changes.

An experiment was conducted (2010-2011) to evaluate the potential impacts of the four climatic scenarios on typical plants used in shoreline restorations. Four outdoor mesocosom $(4.5 \times 4.5 \times 1 \mathrm{~m})$ were constructed at University of Minnesota St. Anthony Falls Laboratory $\left(44^{\circ} 58^{\prime} \mathrm{N}, 93^{\circ} 15^{\prime} \mathrm{W}\right)$. Two sets of four plants 
designated as "drier" and "wetter" were planted (0.3 m apart) in the basin. Each basin was subjected to a water level regime representative of one of the four climatic scenarios. Meteorological, water, soils, and plant growth data were monitored and recorded throughout the seasons. The "wetter" plants outperformed the "drier" plants under all four different water level regimes as measured by the above ground biomass and plant heights. However, the plant performance within each type was different in each basin (Fig. 5). The findings will aid in developing a set of recommendations in selecting shoreline restoration plants most adaptive to climate change.

\subsection{Conclusion}

A 3D coupled hydrodynamic and

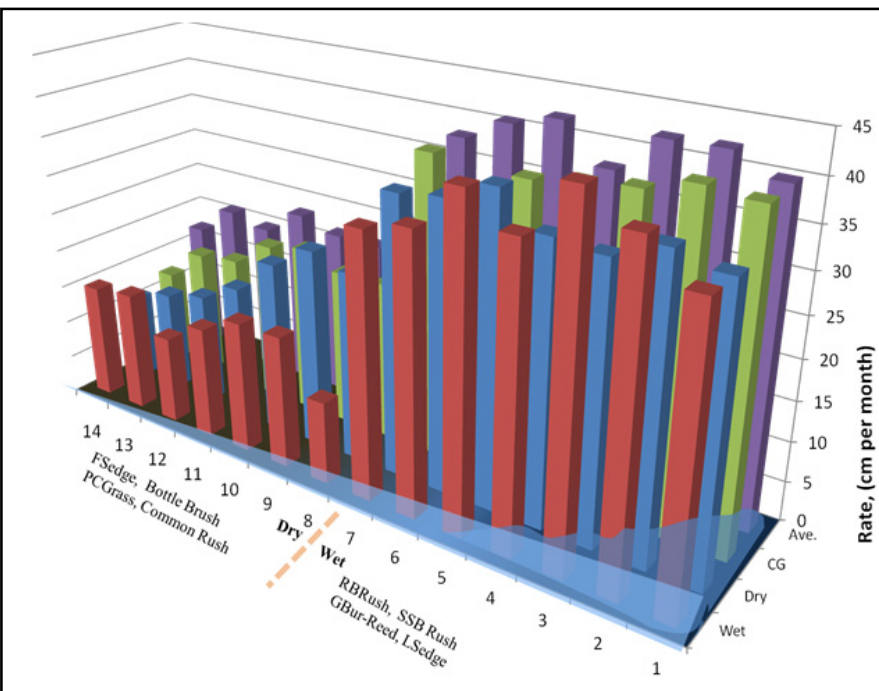

Figure 5. Plant growth rate measured under the four climatic scenarios (mesocosoms).

ecological model was applied in a shallow lake with complex morphology and spatially distributed inflows and outflows. The results show that the lake hydrodynamic and ecological processes are sensitive to mixing due to inflow and wind variabilities over the seasonal stratification. Two sensitivity and uncertainty methods were applied to the model to improve understanding of the model, increase confidence in the model predictions, identify influential model parameters, and quantify the uncertainty of model prediction. The results suggest that spatial and temporal variations of model outputs are sensitive to the hydrodynamics of physical perturbations such as those caused by stream inflows generated from storm events. Two successful examples of the 3D model applications for Lake Minnetonka have been conducted. The findings will aid in developing effective management plans including climate change adaptation strategies.

\section{ACKNOWLEDGMENTS}

The sensitivity and uncertainty analyses included collaboration with Prof. Charles Melching. The Center for Water Research at University of Western Australia provided the ELCOM-CAEDYM software. The Minnehaha Creek Watershed District staff provided the water quality data. The Minnesota Supercomputer Institute provided the use of their computing services and technical assistance. St. Anthony Falls Laboratory staff provided support with the design and construction of the mesocosms. The experiment was funded in part through a grant from EPA Section 319(h) and the University of Minnesota Extension Department. Butler Jessen Water Resources Award and the University of Minnesota Water Resources Graduate Program provided travel and tuition funds for Shahram Missaghi.

\section{REFERENCES}

Arhonditsis G.B., and M. T. Brett. (2004), Evaluation of the Current State of Mechanistic Aquatic Biogeochemical Modeling, Marine Ecology Progress Series, 271 13-26.

Beck, M.B. (1987), Water Quality Modeling: A Review of the Analysis of Uncertainty, Water Resources Research, 23 (8), 1393-1442.

Brown and Caldwell. (2010), San Diego Hydromodification Management Pla, 133904 1-16.

Bruce, L.C., D. Hamilton, J. Imberger, et al. (2006), A Numerical Simulation of the Role of Zooplankton in C, N and P Cycling in Lake Kinneret, Israel, Ecological Modelling, 193 (3-4),412-436.

Cacuci, D. G. (2003), Sensitivity and Uncertainty Analysis: Theory, 304.

Chen, R. Ji, D. J. Schwab, et al. (2002), A Model Study of the Coupled Biological and Physical Dynamics in Lake Michigan, Ecological Modelling, 152 (2-3),145-168.

Coops, M. Beklioglu and T. L. Crisman. (2003), The Role of Water-Level Fluctuations in Shallow Lake ecosystems-workshop Conclusions, Hydrobiologia, 506 (1),23-27.

Fairbairn, D. (2011), Minnesota Water Quality, 10-11.

Gaber, N. (2009), Guidance on the Development, Evaluation, and Application of Environmental Models, Environmental Protection, EPA/100/K-09/003 (March),

Harrison, S.P. (1989), Lake Levels and Climatic Change in Eastern North America, Climate Dynamics, 3 (3), 157-167. 
Missaghi and Hondzo, 3D water quality modeling of a morphologically complex lake...

Hipsey, M.R., G. Gal, J. P. Antenucci, T. Zohary, V. Makler and J. Imberger. (2006), Lake Kinneret Water Quality Management System, Proceedings of the Seventh International Conference on Hydroscience and Engineering,

Hodges, B., J. Imberger, B. Laval and J. Appt. (2000), Modeling the Hydrodynamics of Stratified Lakes, Hydroinformatics 2000 Conference, 4 23-27.

Jorgensen, S.E., and W. Rast. (2007), The use of Models for Synthesizing Knowledge for Integrated Lake Basin Management, and Facilitating Implementation of the World Lake Vision, Lakes \& Reservoirs: Research \& Management, 12 (1),3-13.

Keddy, P.A., and A. A. Reznicek. (1986), Great Lakes Vegetation Dynamics: The Role of Fluctuating Water Levels and Buried Seeds, Journal of Great Lakes Research, 12 (1),25-36.

Kirkman, L.K., and R. R. Sharitz. (1993), Growth in Controlled Water Regimes of Three Grasses Common in Freshwater Wetlands of the Southeastern USA, Aquatic Botany, 44 (4),345-359.

Komatsu, E., T. Fukushima and H. Shiraishi. (2006), Modeling of P-Dynamics and Algal Growth in a Stratified reservoir - mechanisms of P-Cycle in Water and Interaction between Overlying Water and Sediment, Ecological Modelling, 197 (3-4),331-349.

Leon, L.F., R. E. H. Smith, M. R. Hipsey, et al. (2011), Application of a 3D Hydrodynamic-Biological Model for Seasonal and Spatial Dynamics of Water Quality and Phytoplankton in Lake Erie, Journal of Great Lakes Research, 37 41-53.

Loucks, D.P., and E. van Beek. (2005), Water Resources Systems Planning and Management: An Introduction to Methods, Models and Applications. Studies and Reports in Hydrology, United Nations Educational, Scientific and Cultural Organization, 680.

Makler-Pick, V., G. Gal, M. Gorfine, M. R. Hipsey and Y. Carmel. (2011), Sensitivity Analysis for Complex Ecological Models-A New Approach, Environmental Modelling \& Software, 26 124-134.

Manache and C. S. Melching. (2008), Identification of Reliable Regression-and Correlation-Based Sensitivity Measures for Importance Ranking of Water-Quality Model Parameters, Environmental Modelling \& Software, 23 (5),549-562.

Melching, C.S., and W. Bauwens. (2001), Uncertainty in Coupled Nonpoint Source and Stream WaterQuality Models, Journal of Water Resources Planning and Management, 127 (6),403-413.

Mieleitner, J., and P. Reichert. (2008), Modelling Functional Groups of Phytoplankton in Three Lakes of Different Trophic State, Ecological Modelling, 211 (3-4),279-291.

Milly, P.C.D., J. Betancourt, et al. Stationarity is Dead: Whither Water Management? Earth, 420.

Minnehaha Creek Watershed District (MCWD). (2008), 2007 Hydrologic Data Monitoring Report, MCWD, Minnetonka Boulevard Deephaven, MN.

Minnesota Department of Natural Resources (MNDNR). (2007), Lake Minnetonka Status of the Fishery, 2009 (March 3), MNDNR, St. Paul, MN.

Nilsson, C., and M. Svedmark. (2002), Basic Principles and Ecological Consequences of Changing Water Regimes: Riparian Plant Communities, Environmental management, 30 (4),468-480.

Omlin M., Brun R., Reichert P. (2001), Biogeochemical Model of Lake Zurich: Sensitivity, Identifiability and Uncertainty Analysis, Ecol.Model, 141 (1-3),105-123.

Pahl-Wostl, C., P. Jeffrey, N. Isendahl and M. Brugnach. (2011), Maturing the New Water Management Paradigm: Progressing from Aspiration to Practice, Water Resources Management, 1-20.

Power, M.E., N. Brozovic, C. Bode and D. Zilberman. (2005), Spatially Explicit Tools for Understanding and Sustaining Inland Water Ecosystems, Frontiers in Ecology and the Environment, 3 (1),47-55.

Reynolds, C.S. (2006), Ecology of Phytoplankton,

Salacinska, K., G. Y. El Serafy, F. J. Los and A. Blauw. (2009), Sensitivity Analysis of the Two Dimensional Application of the Generic Ecological Model (GEM) to Algal Bloom Prediction in the North Sea, Ecological Modelling, 221 178-190.

Saloranta and T. Andersen. (2007), MyLake--A Multi-Year Lake Simulation Model Code Suitable for Uncertainty and Sensitivity Analysis Simulations, Ecological Modelling, 207 (1),45-60.

Saltelli, A., M. Ratto, S. Tarantola and F. Campolongo. (2006), Sensitivity Analysis Practices: Strategies for Model-Based Inference, Reliability Engineering \& System Safety, 91 (10-11),1109-1125.

Saltelli, A., S. Tarantola and F. Campolongo. (2000), Sensitivity Analysis as an Ingredient of Modeling, Statistical Science, 15 (4),377-395.

Vanderbosch, D.A., and S. M. Galatowitsch. (2010), An Assessment of Urban Lakeshore Restorations in Minnesota, Ecological Restoration, 28 (1),71.

Zhang, W., and G. B. Arhonditsis. (2009), A Bayesian Hierarchical Framework for Calibrating Aquatic Biogeochemical Models, Ecological Modelling, 220 (18),2142-2161. 